Letter to the Editor

\title{
Determinants and outcomes of atrial fibrillation complicating myocardial infarction: the EURHOBOP study in Portugal
}

\author{
Vânia Ribeiro ${ }^{\mathrm{a}, \mathrm{b}}$, Marta Pereira ${ }^{\mathrm{a}, \mathrm{c}}$, Filipa Melão ${ }^{\mathrm{b}}$, Sílvia Marta Oliveira ${ }^{\mathrm{b}}$, Carla Araújo ${ }^{\mathrm{a}, \mathrm{c}, \mathrm{d}}$, Joan Vila ${ }^{\mathrm{e}}$, \\ Paula Dias ${ }^{\mathrm{a}, \mathrm{b}}$, Ana Azevedo ${ }^{\mathrm{a}, \mathrm{c}, *}$ \\ a EPIUnit - Institute of Public Health, University of Porto, Porto, Portugal \\ b Department of Cardiology, Centro Hospitalar São João EPE, Porto, Portugal \\ c Department of Clinical Epidemiology, Predictive Medicine and Public Health, University of Porto Medical School, Porto, Portugal \\ d Department of Cardiology, Centro Hospitalar de Trás-os-Montes e Alto Douro EPE, Vila Real, Portugal \\ e Group on Cardiovascular Epidemiology and Genetics, IMIM (Hospital del Mar Medical Research Institute), Barcelona, Spain
}

\section{A R T I C L E I N F O}

\section{Article history:}

Received 3 August 2014

Accepted 5 August 2014

Available online 13 August 2014

\section{Keywords:}

Atrial fibrillation

Myocardial infarction

Myocardial ischemia

Atrial fibrillation (AF) is a common complication of acute myocardial infarction (AMI) associated with increased mortality [1]; however newonset $\mathrm{AF}$ is less well characterized according to the type of AMI. We sought to study the incidence, predictors and prognosis of new-onset AF complicating ST-segment elevation AMI (STEMI) and non-STsegment elevation AMI (NSTEMI).

Data was derived from the Portuguese sample of EURHOBOP (European Hospital Benchmarking by Outcomes in acute coronary syndrome Processes), a multicenter retrospective study of patients hospitalized with an acute coronary syndrome (ACS). The discharge notes and medical files were retrospectively reviewed by trained data extractors. A patient was considered to have new AF if the arrhythmia appeared at any time during hospitalization. Patients with previous diagnosis of AF described in medical records were excluded. The final sample included 977 episodes of STEMI and 1357 of NSTEMI. This study was approved by the ethics committee of Hospital de São João and the National Commission for Data Protection.

The cumulative incidence of new-onset AF during the hospitalization was $8.9 \%$ and there was no difference according to the type of AMI (STEMI and NSTEMI) ( $8.8 \%$ vs $9.0 \%, \mathrm{p}=0.87$; respectively).

\footnotetext{
* Corresponding author at: Department of Clinical Epidemiology, Predictive Medicine and Public Health, University of Porto Medical School, Alameda Prof. Hernâni Monteiro, 4200-319 Porto, Portugal. Tel.: + 351 225513652; fax: + 351225513653.

E-mail address: anazev@med.up.pt (A. Azevedo).
}

The incidence of AF increased with age in both STEMI ( $<60$ years: $3.1 \% ; \geq 60<80$ years: $11.8 \% ; \geq 80$ years: $17.0 \%, p<0.01)$ and NSTEMI $(2.3 \%, 10.9 \%$ and $14.3 \%$, respectively, $\mathrm{p}<0.01)$. Other clinical characteristics associated with new-onset AF were different in STEMI and NSTEMI (Table 1). In STEMI, LV systolic dysfunction, coronary anatomy, peak troponin and invasive treatment were not associated with newonset AF. On the other hand, in NSTEMI revascularization procedures [percutaneous coronary intervention $(\mathrm{PCI})$ or thrombolysis] reduced the risk of new-onset $\mathrm{AF}$ ( $5.6 \%$ vs $11.2 \%, \mathrm{p}<0.01$ ). Peak troponin level was also marginally associated with AF in NSTEMI (from $8.4 \%$ in the first quartile of troponin I to $14.2 \%$ in the fourth, $p=0.09$ ). Among NSTEMI patients who underwent coronary angiography, increasing severity of coronary anatomy increased the risk of new-onset AF (1-, 2and 3-vessel disease: $4.1 \%, 6.0 \%$, and $8.2 \%$, respectively, $\mathrm{p}=0.14$ ) (Table 1).

In multivariate analysis (Table 2), advanced age was an independent predictor of new-onset AF in STEMI (OR 4.20; 95\% CI 2.11-8.37 and OR 6.73 ; $95 \%$ CI $2.94-15.40$ for $60-79$ years and $\geq 80$ years, respectively) and NSTEMI (OR 5.24; 95\% CI 2.47-11.11 and OR 6.25; 95\% CI 2.7414.26 for $60-79$ years and $\geq 80$ years, respectively). Revascularization procedures reduced the risk of new-onset AF in NSTEMI by a half (age-, sex-, peak troponin- and LV-systolic-function-adjusted OR 0.46; $95 \% \mathrm{CI} 0.28-0.78$ ) and peak troponin I level $>37.00 \mathrm{ng} / \mathrm{mL}$ was associated with new-onset AF in NSTEMI (age, sex, treatment- and LVSDadjusted OR 1.96; 95\% CI 1.02-3.75). Sex and LV systolic function were not independent predictors of new-onset AF in either STEMI or NSTEMI.

In the total sample 459 cases of HF (19.1\% in STEMI and 20\% in NSTEMI groups) and 154 deaths were registered (9.5\% in STEMI and $4.5 \%$ in NSTEMI). New-onset AF was associated with a higher risk of the composite endpoint of clinical HF or death (43.3\% vs $22.0 \%$, $\mathrm{p}<0.01$ ). This association was significant, when adjusting for age, sex, LV systolic function and revascularization in both STEMI (OR 2.89; 95\% CI 1.75-4.80) and NSTEMI (OR 1.69; 95\% CI 1.11-2.58) patients ( $\mathrm{p}$ for interaction $=0.18$ ).

The major study that examined the occurrence of new-onset AF according to the AMI presentation type showed that AF was associated with older age, female sex, higher admission heart rate and hypertension history, in the STEMI and NSTEMI groups [2]. It did not analyze the relation between new-onset AF and LV systolic dysfunction, 
Incidence of new-onset atrial fibrillation according to demographic and clinical characteristics.

\begin{tabular}{|c|c|c|c|c|c|c|}
\hline & \multirow{2}{*}{\multicolumn{2}{|c|}{ Total sample }} & \multicolumn{4}{|l|}{ Type of AMI } \\
\hline & & & \multicolumn{2}{|l|}{ STEMI } & \multicolumn{2}{|l|}{ NSTEMI } \\
\hline & Incidence of $\mathrm{AF}, \mathrm{n}(\%)$ & $\mathrm{p}$ & Incidence of AF, $\mathrm{n}(\%)$ & $\mathrm{p}$ & Incidence of $\mathrm{AF}, \mathrm{n}(\%)$ & $\mathrm{p}$ \\
\hline Age (years), n (\%) & & $<0.01$ & & $<0.01$ & & $<0.01$ \\
\hline$<60$ & $22(2.7)$ & & $13(3.1)$ & & $9(2.3)$ & \\
\hline $60-79$ & $128(11.2)$ & & $50(11.8)$ & & $78(10.9)$ & \\
\hline$\geq 80$ & $58(15.3)$ & & $23(17)$ & & $35(14.3)$ & \\
\hline Sex, n (\%) & & 0.02 & & 0.49 & & 0.016 \\
\hline Female & $80(10.9)$ & & $24(9.9)$ & & $56(11.5)$ & \\
\hline Male & $128(8.0)$ & & $62(8.4)$ & & $66(7.6)$ & \\
\hline Peak troponin I (ng/mL), n (\%) & & 0.16 & & 0.50 & & 0.09 \\
\hline$<2.84$ & $43(8.4)$ & & $8(8.6)$ & & $35(8.4)$ & \\
\hline $2.84-11.00$ & $37(7.2)$ & & $8(6.4)$ & & $29(7.5)$ & \\
\hline $11.01-37.00$ & $49(9.6)$ & & $18(7.6)$ & & $31(11.3)$ & \\
\hline$>37.00$ & $57(11.2)$ & & $40(10.3)$ & & $17(14.2)$ & \\
\hline Peak troponin $\mathrm{T}(\mathrm{ng} / \mathrm{mL}), \mathrm{n}(\%)^{\mathrm{b}}$ & & 0.32 & & 0.51 & & 0.87 \\
\hline$<0.57$ & $3(4.9)$ & & 0 & & $3(5.8)$ & \\
\hline $0.57-1.78$ & $4(6.6)$ & & $1(5.6)$ & & $3(7.0)$ & \\
\hline $1.79-4.32$ & $4(6.6)$ & & $3(10.0)$ & & $1(3.2)$ & \\
\hline$>4.32$ & $8(13.3)$ & & $7(14.3)$ & & $1(9.1)$ & \\
\hline Coronary anatomy ${ }^{\mathrm{c}}, \mathrm{n}(\%)$ & & 0.33 & & 0.70 & & 0.14 \\
\hline 1-vessel disease & $42(6.0)$ & & $30(7.3)$ & & $12(4.1)$ & \\
\hline 2-vessels disease & $34(7.4)$ & & $19(9.2)$ & & $15(6.0)$ & \\
\hline 3-vessels disease & $31(8.3)$ & & $11(8.5)$ & & $20(8.2)$ & \\
\hline Treatment, $\mathrm{n}(\%)$ & & $<0.01$ & & 0.08 & & $<0.01$ \\
\hline Invasive $^{\mathrm{d}}$ & $88(6.9)$ & & $58(7.9)$ & & $30(5.6)$ & \\
\hline Conservative & $120(11.3)$ & & $28(11.6)$ & & $92(11.2)$ & \\
\hline LV systolic function & & $<0.01$ & & 0.22 & & 0.01 \\
\hline Normal $(E F \geq 40 \%)$ & $123(8.5)$ & & $53(8.8)$ & & $70(8.3)$ & \\
\hline Abnormal $(\mathrm{EF}<40 \%)$ & $52(12.7)$ & & $22(11.2)$ & & $30(14.1)$ & \\
\hline Unknown & $33(6.8)$ & & $11(6.1)$ & & $22(7.2)$ & \\
\hline
\end{tabular}

Totals may differ due to missing data.

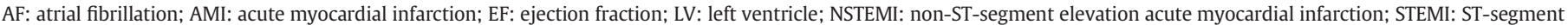
elevation acute myocardial infarction.

a Troponin I applies to 2088 patients from 9 hospitals.

b Troponin T applies to 246 from 1 hospital.

c Among patients who underwent coronary angiography.

d STEMI: invasive treatment comprises thrombolysis, PCI and/or CABG; NSTEMI: invasive treatment comprises PCI and/or CABG.

coronary anatomy, peak troponin or management (invasive vs conservative). Also the association between the severity of AMI presentation and $\mathrm{AF}$ incidence is not consistent. While some studies clearly showed that AF was more common in STEMI than in NSTEMI [3,4], in others AF occurred in similar frequency regardless of AMI type [5] or was even higher in NSTEMI [6]. In our study STEMI vs NSTEMI nature of myocardial damage did not influence the propensity to develop inhospital AF.

AF occurrence during AMI may reflect the influence of myocardial ischemia, leading to left ventricular failure or significant diastolic left ventricular dysfunction, and consequently increasing atrial stretch [7]. P-wave duration and dispersion observed in patients with AMI and AF were abolished after reperfusion with either thrombolysis or primary PCI [8], reinforcing the role of ischemia in arrhythmia development. These observations are consistent with angiographic findings of a significantly higher proportion of patients with new-onset AF having more severe multivessel or left main coronary artery disease [4]. In our NSTEMI group, increasing severity of coronary anatomy increased the new-onset AF incidence and revascularization procedures reduced the risk of AF by almost half. We interpret this finding as evidence that myocardial ischemia contributes to AF in NSTEMI patients. We hypothesize that the same pattern was not observed in STEMI patients because these are more often revascularized, as occurred in our study (invasive treatment in $75 \%$ of STEMI and $40 \%$ of NSTEMI population).

AF is commonly considered an independent marker of poor prognosis. Virtually all studies have reported that patients with AF after AMI experienced higher short- and long-term mortality rates $[1,2,9,10]$.
Our findings were consistent with poorer in-hospital outcomes (clinical heart failure or death) during hospitalization, regardless of AMI type (STEMI vs NSTEMI).

Certain limitations of our study must be acknowledged. First this was a retrospective analysis, having the limitations inherent to such a study design. Second, patients who had prior AF were excluded, but some cases not reported in clinical records may have been classified as having AF as an AMI complication. Finally, timing of AF in relation to coronary reperfusion was not recorded.

In conclusion, new-onset AF was common in patients hospitalized with AMI with an identical incidence between STEMI and NSTEMI. Old age was the strongest predictor of the development of new-onset AF in AMI. In NSTEMI myocardial ischemia may be contributing to newonset AF. New-onset AF was associated with a 2-to-3-fold increase in death or heart failure. The significant impact of new-onset AF in AMI warrants attention towards this arrhythmia and reinforces the instigation for an aggressive approach to avoid myocardial ischemia.

\section{Funding}

This work was supported by Executive Agency for Health and Consumers (2008 1312 - EURHOBOP).

\section{Conflict of interest}

The authors declare that there is no conflict of interest. 
Table 2

Predictors of new-onset atrial fibrillation.

\begin{tabular}{|c|c|c|}
\hline & \multicolumn{2}{|l|}{ Type of AMI } \\
\hline & \multirow{2}{*}{$\begin{array}{l}\text { STEMI } \\
\mathrm{n}=845 \\
\mathrm{OR}(95 \% \mathrm{CI})^{\mathrm{a}}\end{array}$} & \multirow{2}{*}{$\begin{array}{l}\text { NSTEMI } \\
\mathrm{n}=1198 \\
\text { OR }(95 \% \mathrm{CI})^{\mathrm{a}}\end{array}$} \\
\hline & & \\
\hline \multicolumn{3}{|l|}{ Age (years) } \\
\hline$<60$ & 1 & 1 \\
\hline $60-79$ & $4.20(2.11-8.37)$ & $5.24(2.47-11.11)$ \\
\hline$\geq 80$ & $6.73(2.94-15.40)$ & $6.25(2.74-14.26)$ \\
\hline \multicolumn{3}{|l|}{ Sex } \\
\hline Male & 1 & 1 \\
\hline Female & $0.86(0.48-1.52)$ & $1.23(0.81-1.87)$ \\
\hline \multicolumn{3}{|c|}{ Peak troponin I (ng/mL), $n(\%)$} \\
\hline$<2.84$ & 1 & 1 \\
\hline $2.84-11.00$ & $0.88(0.31-2.49)$ & $0.77(0.45-1.29)$ \\
\hline $11.01-37.00$ & $0.98(0.40-2.40)$ & $1.37(0.80-2.32)$ \\
\hline$>37.00$ & $1.39(0.61-3.18)$ & $1.96(1.02-3.75)$ \\
\hline \multicolumn{3}{|l|}{ Treatment } \\
\hline Conservative & 1 & 1 \\
\hline Invasive $^{\mathrm{b}}$ & $0.61(0.35-1.07)$ & $0.46(0.28-0.78)$ \\
\hline \multicolumn{3}{|l|}{ LV systolic function } \\
\hline Normal (EF $\geq 40 \%)$ & 1 & 1 \\
\hline Abnormal $(\mathrm{EF}<40 \%)$ & $0.75(0.38-1.46)$ & $1.22(0.72-2.06)$ \\
\hline Unknown & $0.51(0.24-1.06)$ & $0.62(0.36-1.04)$ \\
\hline
\end{tabular}

AF: atrial fibrillation; AMI: acute myocardial infarction; EF: ejection fraction; LV: left ventricle; NSTEMI: non-ST-segment elevation acute myocardial infarction; STEMI: STsegment elevation acute myocardial infarction.

a Odds ratio adjusted for all variables in the table. Only patients with complete data on all these variables, and from the 9 hospitals where troponin I is used were included.

b STEMI: invasive treatment comprises thrombolysis, PCI and/or CABG; NSTEMI: invasive treatment comprises PCI and/or CABG.

\section{References}

[1] Schmitt J, Duray G, Gersh BJ, Hohnloser SH. Atrial fibrillation in acute myocardial infarction: a systematic review of the incidence, clinical features and prognostic implications. Eur Heart J 2009;30:1038-45.

[2] Lopes RD, Pieper KS, Horton JR, et al. Short- and long-term outcomes following atrial fibrillation in patients with acute coronary syndromes with or without ST-segment elevation. Heart 2008;94:867-73.

[3] Mehta RH, Dabbous OH, Granger CB, et al. Comparison of outcomes of patients with acute coronary syndromes with and without atrial fibrillation. Am J Cardiol 2003;92: 1031-6.

[4] Lau DH, Huynh LT, Chew DP, Astley CM, Soman A, Sanders P. Prognostic impact of types of atrial fibrillation in acute coronary syndromes. Am J Cardiol 2009;104: 1317-23.

[5] Saczynski JS, McManus D, Zhou Z, et al. Trends in atrial fibrillation complicating acute myocardial infarction. Am J Cardiol 2009;104:169-74.

[6] Hersi A, Alhabib KF, Alsheikh-Ali AA, et al. Prognostic significance of prevalent and incident atrial fibrillation among patients hospitalized with acute coronary syndrome: findings from the Gulf RACE-2 registry. Angiology 2012;63:466-71.

[7] Gorenek B, Kudaiberdieva G. Atrial fibrillation in acute ST-elevation myocardial infarction: clinical and prognostic features. Curr Cardiol Rev 2012;8:281-9.

[8] Celik T, Iyisoy A, Kursaklioglu H, et al. Effects of primary percutaneous coronary intervention on P wave dispersion. Ann Noninvasive Electrocardiol 2005;10:342-7.

[9] Rathore SS, Berger AK, Weinfurt KP, Schulman KA, Oetgen WJ, Gersh BJ. Acute myocardial infarction complicated by atrial fibrillation in the elderly: prevalence and outcomes. Circulation 2000;101:969-74.

[10] Lopes RD, White JA, Atar D, et al. Incidence, treatment, and outcomes of atrial fibrillation complicating non-ST-segment elevation acute coronary syndromes. Int J Cardiol 2013;168:2510-7. 